\title{
Optimal parameters and modes of extraction of biologically active substances from natural fruit and berry raw materials
}

\author{
Elena Mironova ${ }^{1,}{ }^{*}$, Elena Romanenko $^{1}$, Olga Sycheva ${ }^{1}$, Maria Selivanova ${ }^{1}$, and \\ Natalia Esaulko ${ }^{1}$ \\ ${ }^{1}$ Stavropol State Agrarian University, lane Zootechnical 12, 355017, Stavropol, Russia
}

\begin{abstract}
Vegetable raw materials serve as a source of a large number of organic compounds of various structures with a variety of preventive and curative nutritional properties. The article presents the results of a study on the establishment of parameters and modes of extraction of biologically active substances from fruit and berry raw materials in order to obtain extracts for the preparation of functional beverages. The work was carried out on the basis of the educational and scientific laboratory of technology of winemaking and food from vegetable raw materials of the Stavropol State Agrarian University according to generally accepted methods in accordance with GOST (State standards). When preparing the extracts, water treatment of the crushed mass of feijoa and blackberries was used. The extraction process was controlled by changing the mass fraction of dry substances. As a result of the research, the optimal conditions for the process of extracting dry substances from feijoa and blackberries were established: hydromodule $-1: 1$, the duration of the process -24 hours; the extraction temperature is 25 degrees $\mathrm{C}$. Such conditions of the process provided the greatest extraction of dry substances without destroying the functional ingredients, allowed the extraction to be carried out within a short period of time and reduced the cost of temperature treatment of the medium. The paper presents the results of tasting evaluation of the obtained extracts.
\end{abstract}

\section{Introduction}

The beverage industry is developing through constant innovation and cutting-edge ideas [12]. At the same time, a promising direction for the development of the food industry is the development and production of functional beverages using plant extracts from domestic raw materials that have a directed biological effect. The creation of new products, the consumption of which can improve the nutritional status of a person is an important component of the concept of healthy nutrition of the Russian population. Plant extracts that are part of beverages not only allow you to simulate the original tastes and aromas of beverages, but also help to increase the body's tone, activate the adaptive capabilities of the nervous system and endocrine glands, increase the body's resistance to adverse environmental factors, and the activity of antioxidant protection of organs and tissues [3]. They are optimal

\footnotetext{
* Corresponding author: elena_st_86@mail.ru
} 
sources of a large number of trace elements that are in a bioavailable, well-digested form [4]. It should be noted that extracts of vegetable raw materials can also be used in the preparation of beverages intended for baby food.

To give drinks functional properties, extracts of medicinal herbs, citrus fruits, stone fruits, seeds, berries, cereals and others are used in their formulations [5-6]. At the same time, the richest sources of vitamins, minerals, enzymes and phenolic compounds, many of which are antioxidants, are fruit and berry extracts [7-9].

In connection with the above we have studied the fundamental possibility of using natural fruit and berry for the preparation of functional drinks based on grape juice. The optimal parameters and modes of extraction of biologically active substances (BAS) from fruit and berry raw materials for obtaining the functional basis of beverages were studied. During the experiment, we pursued the following goals: to extract BAS as much as possible; to provide high organoleptic parameters of extracts; to use affordable and simple technology of the selected method of extraction of biologically active substances.

\section{Materials and methods}

Feijoa fruits and blackberries were used as research objects for the preparation of extracts.

The choice of raw materials is based on the analysis of scientific and technical literature data on its chemical composition, nutritional value and compatibility of organoleptic indicators of extracts in beverages. In addition, we took into account the presence of coloring and aromatic compounds in the raw materials, as well as substances with antimicrobial and antioxidant effects, including those that are not present in grape juice.

The value of the chemical composition of feijoa fruits is often superior to many other crops grown in the southern regions of Russia, as they are a source of biologically important substances, including iodine [10-11], the intake of which in the body with other fruits and berries is very limited.

Blackberries include almost a full range of nutrients and medicinal substances and are the most valuable type of berries in the fresh and processed forms [12]. Blackberries combine sugar with acids, mineral salts and vitamins [13].

In addition to the above, we assumed that feijoa and blackberries grow in the southern regions of Russia in large quantities, but are practically not processed. Thus, their use will expand the raw material base of fruit and berry raw materials, the product range, reduce the cost of transportation of semi-finished products and consequently, reduce the cost of finished products.

In the developed beverage formulations, the main emphasis was on the presence of such functional ingredients as vitamins and phenolcarboxylic acids, minerals and trace elements, the source of which were feijoa and blackberries.

The feijoa variety Gulripshsky, as the richest BAS and having a significant area of plantings in the South of Russia, and the Thornfrey Blackberry variety, as the most common in culture due to its high yield and intense color of berries have been used.

To determine the optimal conditions for the extraction of biologically active substances and physiologically valuable components from the specified fruit and berry raw materials, modern generally accepted research methods were used in accordance with the current GOST (State Standard). Statistical processing of the obtained research results was performed using the software Statistica 6.0 for Windows. The work was carried out on the basis of the educational and scientific laboratory of technology of winemaking and food from plant raw materials of the Stavropol State Agrarian University. 


\section{Results}

It is known that the most accessible and widespread method of obtaining BAS in the food industry is extraction. Thus the efficiency of the process is influenced by such factors as the nature of the extractant, degree of grinding of plant material; temperature and duration of the process; anatomical structure of plant material; difference between concentrations of substances in the system and hydrodynamic conditions; size of the module, i.e. the ratio of "raw materials - extractant".

The extractant used must be safe and accessible, and at the same time be able to extract the compounds necessary for the extraction purpose as much as possible [14].

During the experiment, we used water as an extractant that fully meets the above requirements and allows such compounds as vitamins, phenolic substances, trace elements, as well as organic acids, polysaccharides, and pigments to pass into the liquid. Water has availability, pharmacological and relative chemical indifference. It should be noted that the use of water-alcohol solutions during extraction is impractical due to the further need for de-alcoholization of the obtained extracts.

Extraction was performed at the ratio of raw materials (crushed mass of feijoa/blackberry) and extractant (water) 1:0.5 (option 1), 1:1 (option 2), 1:1.5 (option 3) for 48 hours at a temperature of $20^{\circ} \mathrm{C}$. The extraction took 30 minutes.

Every 8 hours, the extraction process was monitored by changing the mass fraction of dry substances (Fig. 1, 2).

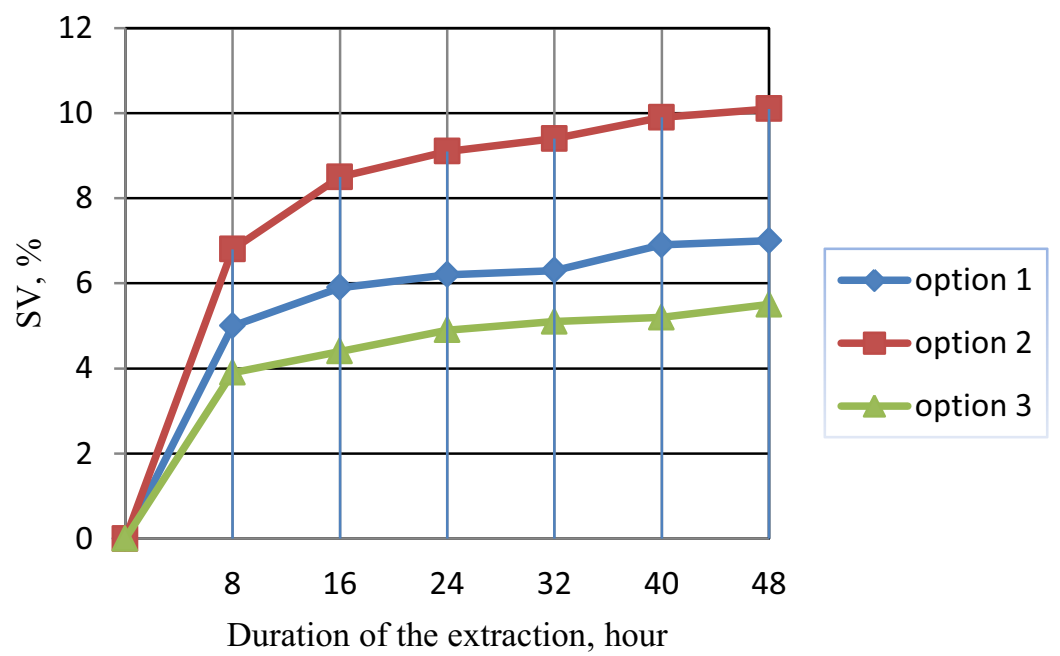

Fig. 1. Dynamics of changes in the mass fraction of dry substances (SV, \%) in feijoa extract depending on the hydromodule.

From the data presented in Fig.s 1 and 2, it can be seen that with an increase in the hydromodule, the degree of dry matter extraction decreased. At the same time, the largest amount of dry substances was extracted in all variants of the experiment for 24 hours. Then the extraction rate decreased, and the mass fraction of dry substances practically did not increase over time.

The experiment was carried out through the statistical processing of the relationship between accumulation in extracts of dry substances, version of the module and duration of the process and the direct correlation between the accumulation of dry substances and the duration of extraction and the inverse relationship between the accumulation of dry matter and 
the ratio of raw material and extractant were identified, however, the correlation coefficient was not statistically significant. This is due to the fact that the dependence of the value of the mass fraction of dry substances $(S V, \%)$ in the studied extracts on the hydromodule variant $(X)$ and the duration of the process $(Y)$ were described by quadratic functions, which can be represented by the equations:

$$
\begin{gathered}
S V, \%, \text { feijoa }=-5,8956+13,2 X+0,1314 Y-3,4417 X^{2}-0,0045 X Y-0,0012 Y^{2} \\
S V \%, \text { blackberry }=-2,3389+6,17 X+0,0856 Y-1,6417 X^{2}-0,0002 X Y-0,001 Y^{2} .
\end{gathered}
$$

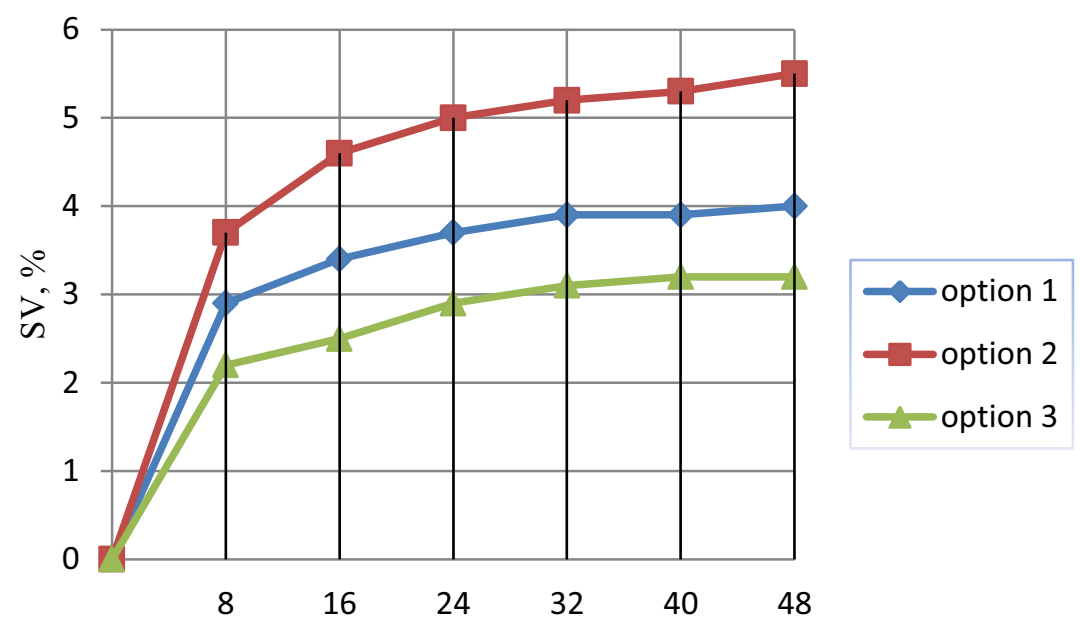

Duration of the extraction, hour

Fig. 2. Dynamics of changes in the mass fraction of dry substances (SV, \%) in blackberry extract depending on the hydromodule.

It should be noted that the maximum value of the mass fraction of dry substances was achieved when the ratio of raw materials and extractant was 1:1 (option 2). So, for feijoa extract with a hydromodule value of $1: 1$, the accumulation of dry substances within 24 hours was $9 \%$, and for blackberry extract $-5 \%$.

It is known that one of the factors that significantly affect the rate of extraction of dry substances is the temperature of the medium. In this regard, we have studied the parameters of the extraction temperature regime. Extraction was performed at a medium temperature of $20^{\circ} \mathrm{C}$ (option 1), $25^{\circ} \mathrm{C}$ (option 2 ), $30^{\circ} \mathrm{C}$ (option 3 ), $35^{\circ} \mathrm{C}$ (option 4) with a 1:1 hydromodule for 48 hours. Every 8 hours, the process was monitored for changes in the mass fraction of dry substances (Fig. 3, 4).

From the data presented in Fig.s 3 and 4, it can be seen that with an increase in the temperature of the medium, the degree of extraction of dry substances increased. At a temperature of $35^{\circ} \mathrm{C}$ in all variants of the experiment, the largest amount of dry substances was extracted, at $20^{\circ} \mathrm{C}$ - the smallest. 


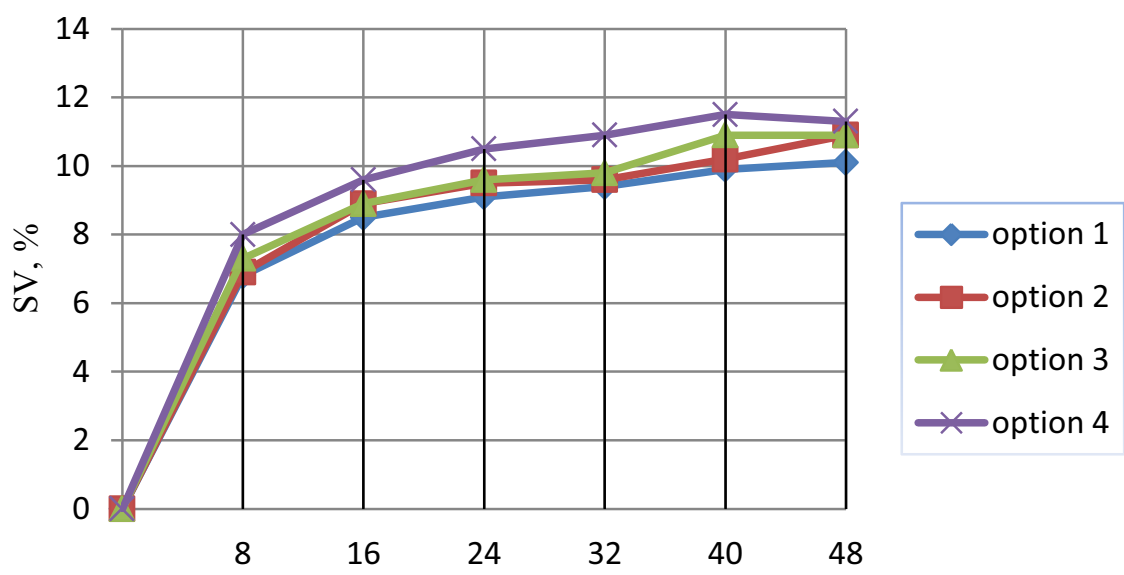

Duration of the extraction, hour

Fig. 3. Dynamics of changes in the mass fraction of dry substances (SV,\%) in feijoa extract depending on the temperature of the environment.

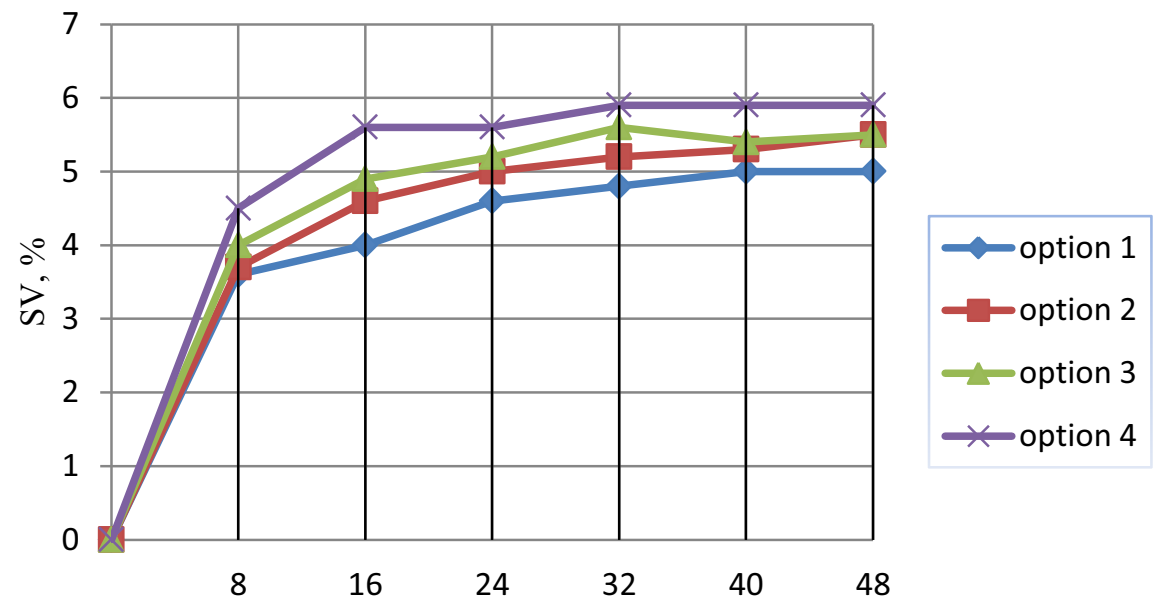

Duration of the extraction, hour

Fig. 4. Dynamics of changes in the mass fraction of dry substances (SV, \%) in blackberry extract depending on the temperature of the environment.

At the same time, by means of the correlation analysis for the studied feijoa extracts, a statistically significant relationship was established between the accumulation of dry substances, the duration of the extraction process, and the temperature of the medium. The correlation coefficient between the dry matter index and the process duration was 0.87 (Fig. 5 ), and the relationship between the extracted dry matter and the medium temperature had a correlation coefficient of 0.37 , which was statistically insignificant (Fig. 6).

At the extraction temperature of $25{ }^{\circ} \mathrm{C}$ and $30{ }^{\circ} \mathrm{C}$, the difference in the concentration of dry substances was insignificant, especially for a certain optimal duration of the process (24 hours) and was 9.5 and $9.6 \%$, respectively (Fig. 6). At the same time, when the temperature increased to $35{ }^{\circ} \mathrm{C}$, the mass fraction of dry substances increased by only $0.5 \%$, respectively, the process was impractical from an economic point of view. Thus, taking into account 
the negative effect of increasing temperature on the composition of extracted components, in particular, a decrease in the concentration of target functional ingredients (vitamins, amino acids), the optimal extraction temperature was $25^{\circ} \mathrm{C}$.

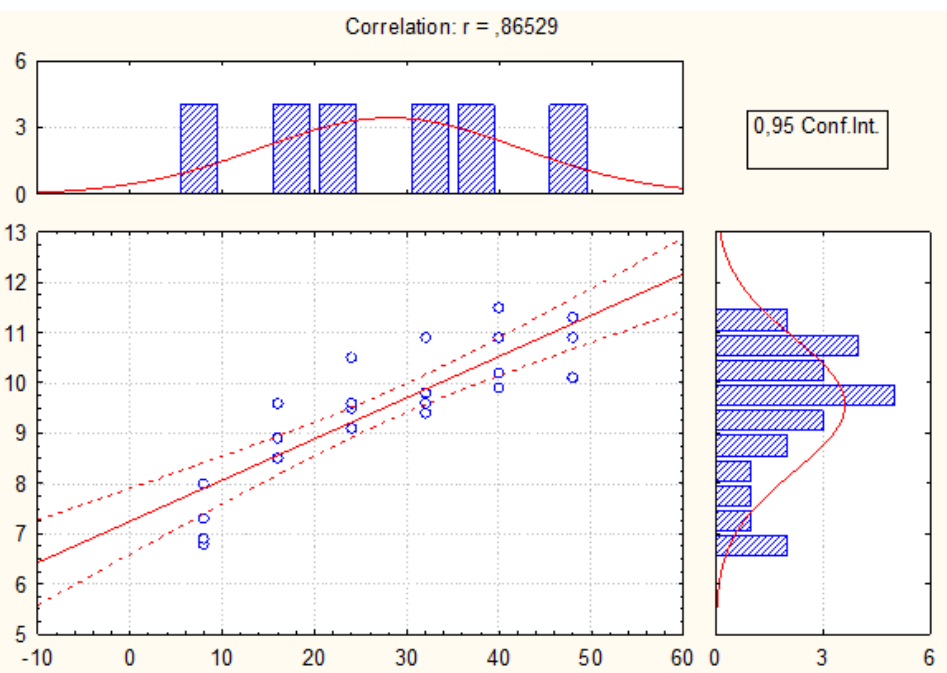

Fig. 5. Correlation dependence of dry matter accumulation (SV, \%) in feijoa extract on the duration of the process.
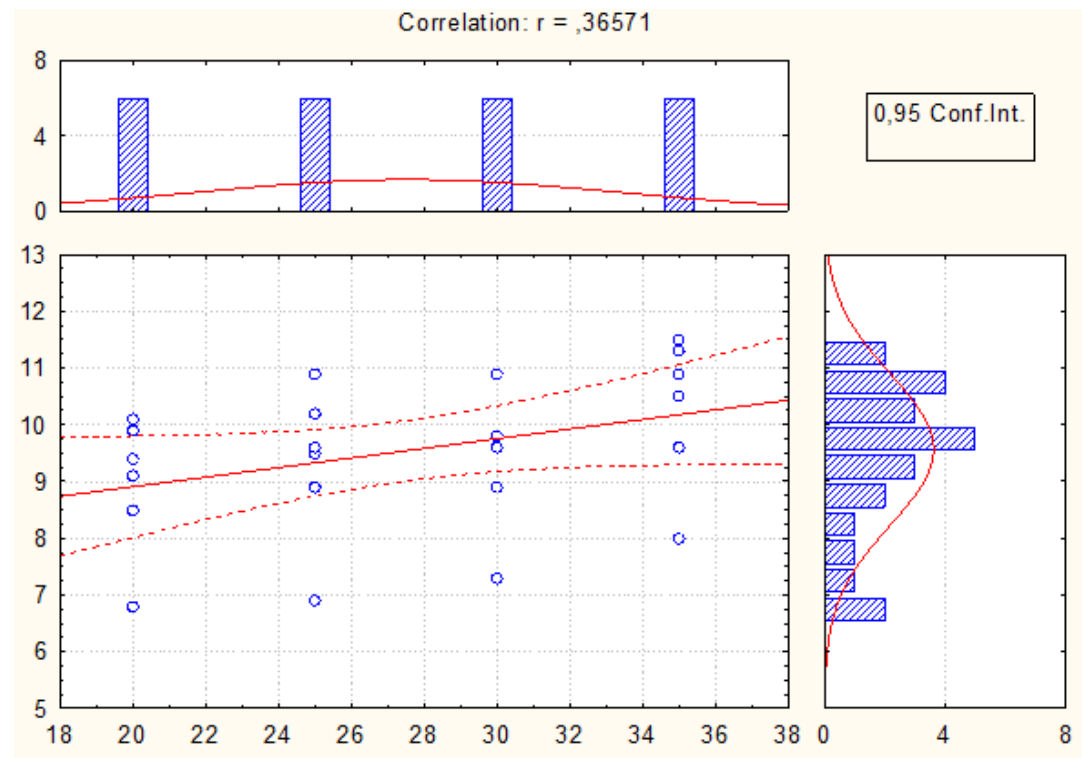

Fig. 6. Correlation dependence of dry matter accumulation (SV, \%) in feijoa extract on the medium temperature.

The dependence of the dry matter content $(S V, \%)$ in feijoa and blackberry extracts on the temperature $(X)$ and duration of extraction $(Y)$ is represented by the equations:

$$
\begin{gathered}
S V, \%, \text { feijoa }=6,56-0,127 X+0,1932 Y+0,0037 X^{2}+0,0004 X Y-0,0022 Y^{2} ; \\
S V, \%, \text { blackberry }=2,1558+0,0683 X+0,0349 Y .
\end{gathered}
$$


For the studied extracts of blackberry through the module descriptive statistics was a positive correlation between the accumulation of dry matter and value of the temperature with correlation coefficient of 0.57 and a positive correlation between the duration of the process and accumulation of dry substances with a correlation coefficient of 0.72 (Fig. 7, 8).

It should be noted that the accumulation of dry substances in the extract of blackberry differed depending on the temperature and duration of extraction and were described by the direct function of the dependence, i.e. with increasing temperature and duration of the process the mass fraction of dry substances in the extracts increased.

However, at a certain optimal duration of the process ( 24 hours) and a temperature of 25 ${ }^{\circ} \mathrm{C}$ and $30{ }^{\circ} \mathrm{C}$, the difference in the concentration of dry substances was insignificant $0.2 \%$. And with a further increase in temperature, the mass fraction of dry substances increased slightly.

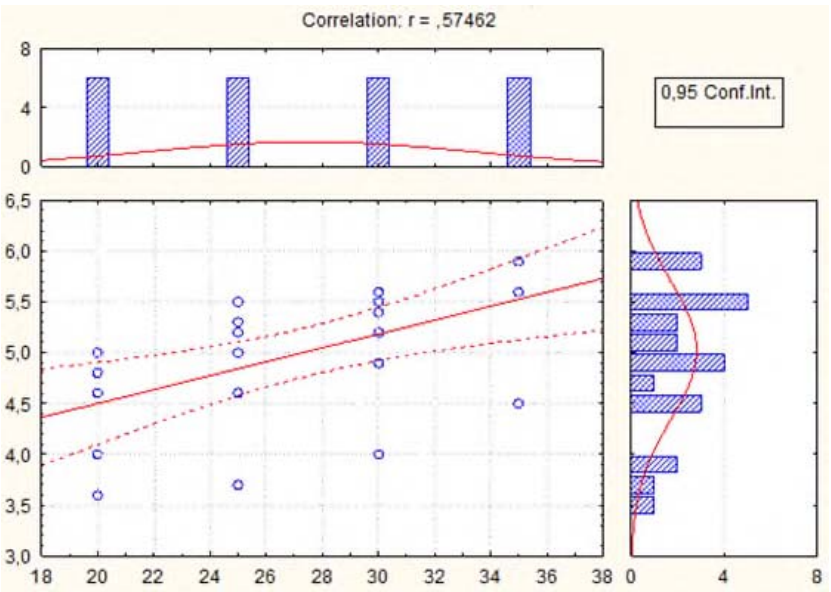

Fig. 7. Correlation dependence of dry matter accumulation (SV, \%) in blackberry extract on the medium temperature.

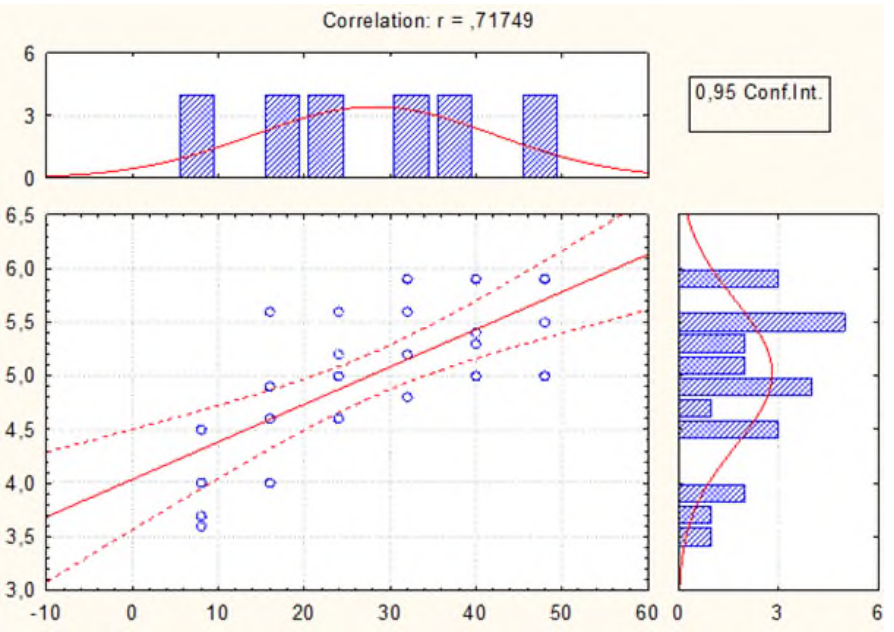

Fig. 8. Correlation dependence of dry matter accumulation (SV, \%) in blackberry extract on the duration of the process.

Thus, the optimal temperature regime for the dry matter extraction process both for blackberries and for feijoa, was a temperature of $25^{\circ} \mathrm{C}$. 


\section{Discussion}

Thus, based on the conducted research, the optimal parameters and modes of the process of extracting dry substances from feijoa fruits and blackberries were determined: duration -24 hours; hydromodule $-1: 1$, temperature- $25{ }^{\circ} \mathrm{C}$. Such process conditions provided the greatest extraction of dry substances without destroying the functional target ingredients, allowed extraction to be carried out within a short period of time and reduced the cost of temperature treatment of the medium.

Tasting evaluation of the obtained extracts was performed after they were diluted with water in a ratio of 1:2. The organoleptic profile of the extracts is shown in Fig. 9.

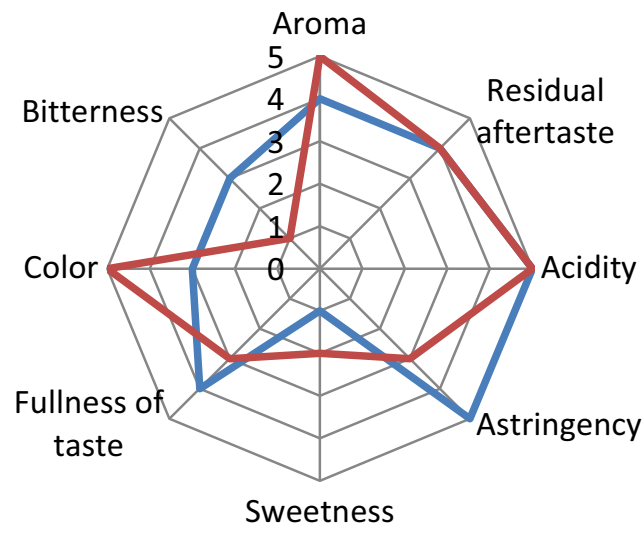

Feijoa

Blackberry

Fig. 9. Organoleptic profile of feijoa and blackberry extracts.

The feijoa extract was characterized by a greenish-brown color, sour, tart taste with resinous tones, had a complex aroma with herbaceous, juniper shades. The original, slightly tart taste of the extract can be explained by the transfer of a large amount of phenolic substances from the raw material during the extraction process [15]. Blackberry extract had a bright crimson color, sour taste, complex aroma with tones of cherry, red and black currant, blackthorn.

\section{References}

1. M. Serafini, A. Stanzione \& S. Foddai, Functional foods: traditional use and European legislation, International, Journal of Food Sciences and Nutrition, 63(sup1), 7-9 (2012) https://doi.org/10.3109/09637486.2011.637488.

2. D. Sun-Waterhouse, The development of fruit-based functional foods targeting the health and wellness market: a review, International, Journal of Food Science \& Technology, 46, 899-920 (2011) doi:10.1111/j.1365-2621.2010.02499.x

3. S. Rodino, M. Butu, Herbal Extracts - New Trends in Functional and Medicinal Beverages, Functional and Medicinal Beverages, 11, 73-108 (2019) https://doi.org/10.1016/B978-0-12-816397-9.00003-0.

4. A. N. M. Alamgir, Therapeutic Use of Medicinal Plants and Their Extracts, 1 (2017) https://doi.org/10.1007/978-3-319-63862-1. 
5. I. Mantzourania, A.Terpoub, A. Bekatoroub, A. Mallouchosc, A. Alexopoulosa, A. Kimbarisa, E. Bezirtzogloua, A. A. Koutinasb, S. Plessas, Functional pomegranate beverage production by fermentation with a novel synbiotic L. paracasei biocatalyst, Food Chemistry, 308, 125658 (2020) https://doi.org/10.1016/j.foodchem.2019.125658.

6. V. K. Atanasova, P. D. Gatseva, Natural Beverages and Their Role as Functional Foods, Natural Beverages, 13, 37-71 (2019) https://doi.org/10.1016/B978-0-12816689-5.00002-X.

7. T. Amofa-Diatuoa, D. M. Ananga, F. J. Barbab, B. K. Tiwaric, Development of new apple beverages rich in isothiocyanates by using extracts obtained from ultrasoundtreated cauliflower by-products: Evaluation of physical properties and consumer acceptance, Journal of Food Composition and Analysis, 61, 73-81 (2017) https://doi.org/10.1016/j.jfca.2016.10.001

8. B. Singh, J. P. Singh, A. Kaur, N. Singh, Phenolic compounds as beneficial phytochemicals in pomegranate (Punica granatum L.) peel: a review, Food Chem., 261, 75 86 (2018) https://doi.org/10.1016/j.foodchem.2018.04.039.

9. J. Pérez-Jiménez, S. Arranz, M. Tabernero, M. E. Díaz-Rubio, J. Serrano, I. Goñi, F. Saura-Calixto, Updated methodology to determine antioxidant capacity in plant foods, oils and beverages: extraction, measurement and expression of results, Food Res. Int., 41, 274-285 (2008) https://doi.org/10.1016/j.foodres.2007.12.004.

10. F. Zhu, Chemical and biological properties of feijoa (Acca sellowiana), Trends in Food Science \& Technology, 81, 121-131 (2018) https://doi.org/10.1016/j.tifs.2018.09.008.

11. M. L. Vuotto, A. Basile, V. Moscatiello, P. De Sole, R. Castaldo-Cobianchi, E. Laghi, M. T. L. Ielpo, Antimicrobial and antioxidant activities of Feijoa sellowiana fruit, International Journal of Antimicrobial Agents, 13(3), 197-201 (2000) https://doi.org/10.1016/S0924-8579(99)00122-3.

12. F. Vaillant, Chapter 25 - Blackberries, Nutritional Composition and Antioxidant Properties of Fruits and Vegetables, 407-422 (2020) https://doi.org/10.1016/B978-0-12812780-3.00025-8.

13. M. Schulz, S. K. T. Seraglio, F. D. Betta, P. Nehring, A. C. Valese, H. Daguer, L. V. Gonzaga, A. C. O. Costa, R. Fett, Blackberry (Rubus ulmifolius Schott): Chemical composition, phenolic compounds and antioxid ant capacity in two edible stages, Food Research International, 122, 627-634 https://doi.org/10.1016/j.foodres.2019.01.034.

14. F. Chemat, M. A. Vian, G. Cravotto, Green Extraction of Natural Products: Concept $\begin{array}{llllll}\text { and Principles, Int. J. Mol. Sci., 13(7), 8615-8627 (2012) } & \end{array}$ https://doi.org/10.3390/ijms13078615.

15. N. B. Tuncel, N. Y1lmaz, Optimizing the extraction of phenolics and antioxidants from feijoa (Feijoa sellowiana, Myrtaceae), J Food Sci Technol., 52, 141-150 (2015) https://doi.org/10.1007/s13197-013-0968-0. 